\section{The effects of the}

topical administration

of non-steroidal antiinflammatory drugs on corneal epithelium and corneal sensitivity in normal subjects
PASQUALE ARAGONA, GIULIANA TRIPODI, ROSARIA SPINELLA EMILIA LAGANÀ, GIUSEPPE FERRERI
P. Aragona

G. Tripodi

R. Spinella

E. Laganà

G. Ferreri

Institute of Ophthalmology

University of Messina

Messina, Italy

Dr Pasquale Aragona Institute of Ophthalmology University of Messina viale Boccetta, 70 I-98122 Messina, Italy

Tel: +3990 343184

Fax: +39 902924819

e-mail: p.aragona@eniware.it

Received: 31 March 1999 Accepted in revised form: 15 September 1999

\begin{abstract}
Purpose To study the changes in the corneal epithelium and corneal sensitivity of healthy subjects after the topical administration of non-steroidal anti-inflammatory drugs (NSAIDs; diclofenac, indomethacin, flurbiprofen and ketorolac) frequently used in ocular therapy.
\end{abstract}

Methods A double-masked parallel clinical study was undertaken on 90 subjects (45 men, 45 women; Caucasian; age $21-46$ years, mean \pm SD $27.1 \pm 5$ years). The subjects were divided into six groups: group 1 was treated with placebo, group 2 with $0.1 \%$ diclofenac, group 3 with $0.1 \%$ indomethacin, group 4 with $0.03 \%$ flurbiprofen, group 5 with $0.5 \%$ ketorolac and group 6 with $0.4 \%$ oxybuprocaine. One eye was randomly treated with the study drug and the fellow eye was treated with placebo. The medications were instilled four times, at $5 \mathrm{~min}$ intervals. Assessment of the corneal epithelium was carried out by vital fluorescein stain before instillation and 5, 15, 30 and 60 min after instillation of the last drop.

Subjective burning sensation was assessed by asking participants to rate burning on a scale from 0 (none) to 3 (severe). After 1 week, assessment of corneal sensitivity was carried out by the Cochet-Bonnet method, repeating the above scheme of instillation and measurement times.

Results None of the study drugs, with the exception of oxybuprocaine, produced evident epithelial damage. All the drugs caused a mean burning sensation greater than the placebo. The diclofenac-treated group showed a statistically significant decrease in corneal sensitivity $(p<0.001)$ at the measurement carried out $15 \mathrm{~min}$ after instillation of the last drop and lasting up to the end of the study, when the corneal anaesthesia was similar to that induced by the topical anaesthetic treatment. No significant changes were demonstrated for the other NSAIDs when compared either with the placebo-treated eyes or with the fellow eyes.

Conclusions Despite a similar mechanism of action and analgesic activity to the other NSAIDs tested, diclofenac was able to induce a reduction in corneal sensitivity. More studies are needed to determine the mechanism of action responsible for this effect.

Key words Corneal sensitivity, Diclofenac, Flurbiprofen, Indomethacin, Ketorolac, Nonsteroidal anti-inflammatory drugs

Non-steroidal anti-inflammatory drugs (NSAIDs) act in reducing fever and alleviating pain that accompanies injury or inflammation. They inhibit cyclooxygenase, an enzyme important for the synthesis of prostaglandins and certain related autacoids. The prostaglandins, produced following injury by activation of the arachidonic acid cascade, induce a state of hyperalgesia by lowering the threshold of activation of the pain afferent nerves. NSAIDs act locally or near the point of injury reducing the prostaglandin-induced hyperalgesia. ${ }^{1}$

The topical ocular use of NSAIDs includes maintenance of pupillary dilatation during surgery, and control of post-operative ocular inflammation and pain, for example following radial keratotomy ${ }^{2}$ or photorefractive keratectomy. ${ }^{3}$ They are also used for the prevention and treatment of post-operative cystoid macular oedema ${ }^{1}$ and for non-surgically induced inflammatory disorders of the eye, such as allergic conjunctivitis. A number of different conditions, either physiological such as ageing, menstrual cycle or pathological like trauma, glaucoma, hypoxia and corneal acidosis after contact lenses wear, herpes simplex keratitis, diabetes, leprosy and trigeminal 
neuralgia, ${ }^{4-8}$ can affect corneal sensitivity. A decreased corneal sensitivity was also described after ocular surgical procedures such as epikeratophakia, ${ }^{9}$ radial keratotomy ${ }^{10}$ and photorefractive keratectomy, ${ }^{11}$ and topical treatment with NSAIDs. ${ }^{12-15}$

Diclofenac sodium is a phenylacetic acid derivative used, in clinical practice, for its analgesic properties. Indomethacin, a methylated indole derivative, exerts its action through a prominent anti-inflammatory activity. Indomethacin also has an analgesic effect distinct from its anti-inflammatory properties with both a central and peripheral action. Flurbiprofen is a propionic acid derivative with a prevalent analgesic effect. ${ }^{16}$ Ketorolac tromethamine is a member of the phenylalkanoic group of NSAIDs, which has shown marked analgesic properties. ${ }^{17}$ The aim of the study was to compare the effect of indomethacin, diclofenac, flurbiprofen and ketorolac on the corneal epithelium and on corneal sensitivity of healthy volunteers.

\section{Material and methods}

Ninety subjects (45 men, 45 women; Caucasian; age 21-46 years, mean \pm SD $27.1 \pm 5$ years) were enrolled in the study. Commercially available drugs were used. Six groups each of 15 healthy volunteers, age and sex matched, were studied.

Group 1, the control group, was treated with placebo with the following solution: boric acid $99.75 \mathrm{mg}$, borax $7.45 \mathrm{mg}$, methyl-p-hydroxybenzoate $2.5 \mathrm{mg}$, polyethylene glycol $4001242.50 \mathrm{mg}$, disodium edetate $2.5 \mathrm{mg}$, purified water quantum sufficit to $5 \mathrm{ml}$ (mean age \pm SD $28.7 \pm 6.9$ years; 8 women, 7 men).

Group 2 was treated with $0.1 \%$ diclofenac (Voltaren Ofta, Ciba Vision Ophthalmics, Hettlingen, Switzerland) (26.2 \pm 4 years; 7 women, 8 men).

Group 3 was treated with $0.1 \%$ indomethacin solution (Indocollirio, SIFI, Catania, Italy) $(26.7 \pm 3.6$ years; 8 women, 7 men).

Group 4 was treated with $0.03 \%$ flurbiprofen (Ocufen, Allergan Pharmaceuticals, Westport, Co. Mayo, Ireland) ( $26.2 \pm 3.3$ years; 7 women, 8 men).

Group 5 was treated with $0.5 \%$ ketorolac tromethamine (Acular, Allergan Pharmaceuticals, Westport, Co. Mayo, Ireland) (24.9 \pm 4 years; 8 women, 7 men).

Group 6 was treated with a topical anaesthetic solution of $0.4 \%$ oxybuprocaine chloridrate (Novesina, Novartis Farma, Orrigio (VA), Italy) ( $30 \pm 6.1$ years; 7 women, 8 men).

Informed consent was obtained from all subjects.

Exclusion criteria were: age over 50 years, contact lens wear, and patients with present ocular diseases or with a history of diseases such as herpetic diseases or with previous ocular surgery. Also excluded were patients who had taken topical or general treatment during the previous month or with systemic diseases such as diabetes.
The eye drops were instilled in one eye 4 times at 5 min intervals and the ocular surface studied by fluorescein stain ${ }^{18}$ before drug instillation and 5, 15, 30 and $60 \mathrm{~min}$ after the last drop was instilled. The fellow eye was treated according to the same procedure, with the drop used in the placebo group. A subjective evaluation of the burning sensation was performed by asking participants to rate burning, after each instillation, on a scale ranging from 0 (none) to 3 (severe).

After 1 week the drugs were instilled again, following the same procedure previously described; the corneal sensitivity measurements were performed before the instillation and 5, 15, 30 and $60 \mathrm{~min}$ after instillation of the last drop, using the Cochet-Bonnet aesthesiometer (Luneau Ophtalmologie, Chartres, France). The instrument consists of a $0.12 \mathrm{~mm}$ diameter nylon filament of variable length (from 0 to $60 \mathrm{~mm}$ ) which is applied on the cornea with a strength variable from 11 to $200 \mathrm{mg} /$ $0.0113 \mathrm{~mm}^{2}$ (mg/S). ${ }^{19}$ The subjects were positioned at the slit-lamp fixating on a distant point with the slit-lamp light positioned at about $60^{\circ}$, with low-intensity illumination. The measurements were started with the filament at its maximal length (lowest pressure), which is $60 \mathrm{~mm}$. The filament was advanced perpendicularly and the cornea touched gently. Measurements were taken at the central cornea and in the four peripheral quadrants. A positive response was registered when the subject declared verbally the sensation of corneal touch. The simple reflex blinking of the tested eye was not recorded as a positive response. If a positive response was not achieved the filament length was reduced by $5 \mathrm{~mm}$ and the procedure repeated. The filament length that determined the corneal sensation was registered and converted into milligrams/surface unit (mg/S) according to a table supplied by the instrument manufacturer.

The study was performed with a double-masked design since both the subjects and the examiner were masked as to which eye received the drug.

For statistical analysis of the results of corneal epithelial damage Fisher's exact test was used; the results of corneal sensitivity (in $\mathrm{mg} / \mathrm{S}$ ) were carried out considering for each eye the mean value obtained from the measurements of the five areas considered. Analysis was performed using an analysis of variance. Results were expressed as the mean $\pm \mathrm{SD}$. A $p$ value of $\leqslant 0.05$ was considered statistically significant.

\section{Results}

No signs of corneal epithelial damage were found in the patients of the five groups treated with placebo or with NSAIDs at any time of the study. Four subjects treated with the topical anaesthetic showed mild corneal epithelial defects (score 1 according to Lemp ${ }^{18}$ ) already present at $5 \mathrm{~min}$ after instillation of the last drop and lasting up to the observation at $60 \mathrm{~min}(p=0.04)$.

All groups instilled with NSAIDs complained of a mild burning sensation lasting a few seconds after each instillation. The grading of the subjective burning 


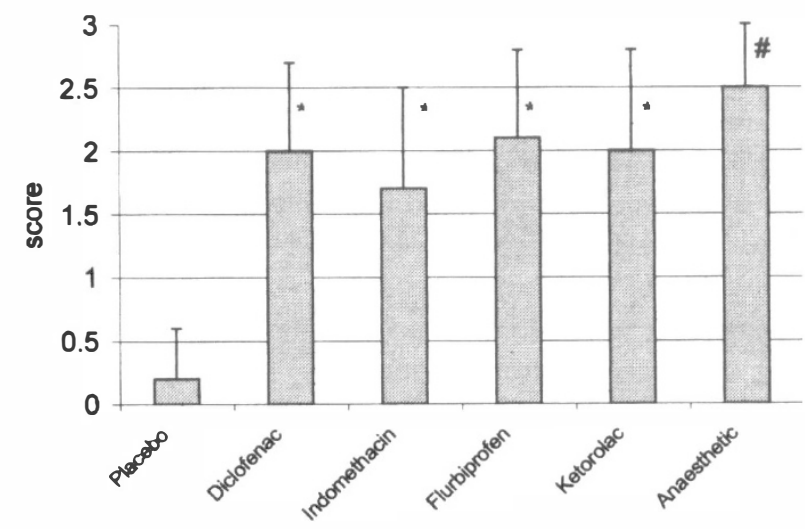

Fig. 1. Mean burning sensation obtained considering the results reported at each of the four instillations, in the six treatment groups. ${ }^{*} \mathrm{p}<0.000001$ versus placebo-treated group. $\# \mathrm{p}=0.0000001$ versus group $1 ; \mathrm{p}=0.03$ versus group $2 ; \mathrm{p}=0.002$ versus group $3 ; \mathrm{p}=0.08$ versus group $4 ; \mathrm{p}=0.05$ versus group 5 .

sensation, reported as the mean of the grades after each instillation, showed a statistically significantly higher mean score in subjects instilled with NSAIDs compared with the placebo-treated group $(p<0.000001)$. Also, patients in the oxybuprocaine-treated group showed a statistically significantly higher burning sensation after each instillation compared with the subjects in the other groups, with the exception of the flurbiprofen-treated group (Fig. 1).

The results of corneal sensitivity for the six treatment groups are shown in Table 1. Before administration of the eye drops all subjects had corneal sensitivity values of 11-12 mg/S. A decrease in corneal sensitivity was demonstrated in diclofenac-treated eyes at the measurement carried out $15 \mathrm{~min}$ after instillation of the last drop and lasting up to the end of the study. This was statistically significant when compared with either the treatment with other NSAIDs (Fig. 2) or the fellow eyes (Table 1). The oxybuprocaine-treated subjects showed a profound reduction in corneal sensitivity (beyond the measurement capability of the instrument) $5 \mathrm{~min}$ after

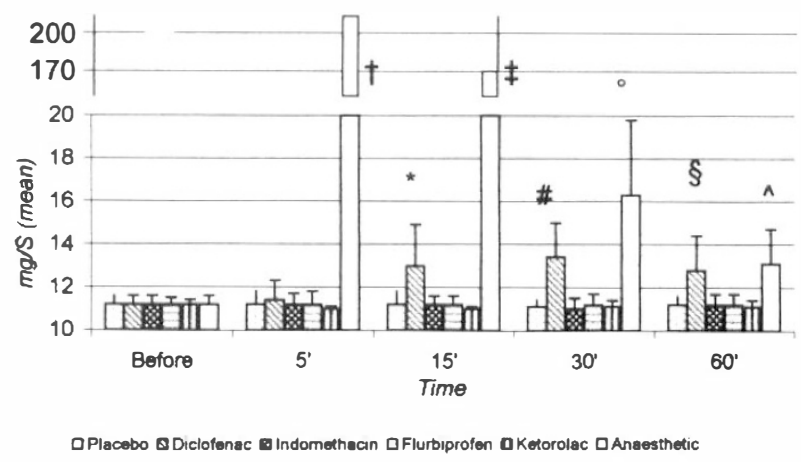

Fig. 2. Mean decrease in corneal sensitivity in the diclofenac-treated group, expressed as an increase in weight/surface unit $\left(0.0113 \mathrm{~mm}^{2}\right)$ necessary to evoke a mechanical sensation on the corneal surface. ${ }^{*} \mathrm{p}=0.0015$ versus group $1 ; \mathrm{p}=0.0012$ versus group $3 ; \mathrm{p}=0.0012$ versus group $4 ; \mathrm{p}=0.0003$ versus group 5 . \# $\mathrm{p}=0.0000076$ versus group $1 ; \mathrm{p}=0.0000061$ versus group $3 ; \mathrm{p}=0.000021$ versus group $4 ;$ $\mathrm{p}=0.0000076$ versus group $5 . \S \mathrm{p}=0.0008$ versus group 1 ; $\mathrm{p}=0.00094$ versus group $3 ; \mathrm{p}=0.00094 ; \mathrm{p}=0.00037$ versus group 5 . $\dagger \mathrm{p}<10^{-6}$ versus all other groups. $\neq \mathrm{p}<10^{-6}$ versus all other groups. ${ }^{\circ} \mathrm{p}=0.000003$ versus group $1 ; \mathrm{p}=0.006$ versus group $2 ; \mathrm{p}=$ 0.000002 versus group $3 ; \mathrm{p}=0.000005$ versus group $4 ; \mathrm{p}=0.000003$ versus group $5 . \wedge \mathrm{p}=0.0001$ versus group $1 ; \mathrm{p}=0.6$ versus group $2 ; \mathrm{p}$ $=0.0001$ versus group $3 ; \mathrm{p}=0.0001$ versus group $4 ; \mathrm{p}=0.00005$ versus group 5 .

instillation of the last drop. Corneal sensitivity was also markedly reduced at the $15 \mathrm{~min}$ measurement, and a significant reduction was still present at $30 \mathrm{~min}$ and $60 \mathrm{~min}$. At the $60 \mathrm{~min}$ measurement corneal sensitivity was not significantly different from that of the diclofenac-treated group $(p=0.6)$, both treatments showing a significant reduction in sensitivity compared with eyes treated with either placebo or other NSAIDs.

A statistical comparison between the corneal sensitivity values of indomethacin-, flurbiprofen- and ketorolac-treated eyes with the respective fellow control eyes treated with placebo, and with the eyes of the placebo-treated group, did not show any significant difference at any time. Nor was there any statistically significant difference versus the baseline values.

Table 1. Mean corneal sensitivity ( \pm SD), expressed in $\mathrm{mg} / \mathrm{surface}$ unit $\left(0.0113 \mathrm{~mm}^{2}\right)$, in the five groups of subjects

\begin{tabular}{|c|c|c|c|c|c|c|}
\hline & & \multirow[b]{2}{*}{ Before treatment } & \multicolumn{4}{|c|}{ After treatment } \\
\hline & & & $5 \mathrm{~min}$ & $15 \mathrm{~min}$ & $30 \mathrm{~min}$ & $60 \mathrm{~min}$ \\
\hline \multirow[t]{3}{*}{ Group 1} & Placebo & $11.2 \pm 0.4$ & $11.2 \pm 0.6$ & $11.2 \pm 0.6$ & $11.1 \pm 0.3$ & $11.2 \pm 0.4$ \\
\hline & Placebo & $11.2 \pm 0.6$ & $11.2 \pm 0.6$ & $11.2 \pm 0.4$ & $11.2 \pm 0.4$ & $11.2 \pm 0.6$ \\
\hline & $p=$ & 1 & 1 & 1 & 0.44 & 1 \\
\hline \multirow[t]{3}{*}{ Group 2} & Diclofenac & $11.2 \pm 0.4$ & $11.4 \pm 0.9$ & $13.0 \pm 1.9$ & $13.4 \pm 1.6$ & $12.8 \pm 1.6$ \\
\hline & Placebo & $11.1 \pm 0.2$ & $11.1 \pm 0.4$ & $11.1 \pm 0.4$ & $11.1 \pm 0.4$ & $11.1 \pm 0.4$ \\
\hline & $p=$ & 0.39 & 0.24 & 0.0007 & 0.000009 & 0.0004 \\
\hline \multirow[t]{3}{*}{ Group 3} & Indomethacin & $11.2 \pm 0.4$ & $11.2 \pm 0.5$ & $11.2 \pm 0.4$ & $11.0 \pm 0.5$ & $11.2 \pm 0.5$ \\
\hline & Placebo & $11.2 \pm 0.6$ & $11.2 \pm 0.5$ & $11.1 \pm 0.4$ & $11.2 \pm 0.3$ & $11.2 \pm 0.6$ \\
\hline & $p=$ & 1 & 1 & 0.49 & 0.19 & 1 \\
\hline \multirow[t]{3}{*}{ Group 4} & Flurbiprofen & $11.2 \pm 0.3$ & $11.2 \pm 0.6$ & $11.2 \pm 0.4$ & $11.2 \pm 0.5$ & $11.2 \pm 0.5$ \\
\hline & Placebo & $11.2 \pm 0.6$ & $11.2 \pm 0.5$ & $11.2 \pm 0.5$ & $11.1 \pm 0.3$ & $11.2 \pm 0.5$ \\
\hline & $p=$ & 1 & 1 & 1 & 0.51 & 1 \\
\hline \multirow[t]{3}{*}{ Group 5} & Ketorolac & $11.1 \pm 0.2$ & $11 \pm 0.1$ & $11 \pm 0.1$ & $11.1 \pm 0.3$ & $11.1 \pm 0.3$ \\
\hline & Placebo & $11.1 \pm 0.3$ & $11.1 \pm 0.2$ & $11 \pm 0.2$ & $11.1 \pm 0.2$ & $11.1 \pm 0.2$ \\
\hline & $p=$ & 1 & 0.09 & 1 & 1 & 1 \\
\hline \multirow[t]{3}{*}{ Group 6} & Oxybuprocaine & $11.2 \pm 0.4$ & $>200$ & $128.6 \pm 64.2$ & $16.3 \pm 3.5$ & $13.1 \pm 1.6$ \\
\hline & Placebo & $11.1 \pm 0.6$ & $11.2 \pm 0.5$ & $11.3 \pm 0.4$ & $11.3 \pm 0.4$ & $11.2 \pm 0.6$ \\
\hline & $p=$ & 0.59 & $<10^{-6}$ & $<10^{-6}$ & 0.000006 & 0.0001 \\
\hline
\end{tabular}




\section{Discussion}

The present study has shown a statistically significant decrease in corneal sensitivity in diclofenac-treated eyes. This effect appeared at the measurement performed $15 \mathrm{~min}$ after instillation of the last drop and lasted throughout the study. A similar effect was not induced by treatment with the other NSAIDs tested.

Diclofenac, indomethacin, flurbiprofen and ketorolac have an anti-inflammatory effect mediated by the inhibition of the cyclooxygenase pathway of the arachidonic acid cascade. These drugs also have analgesic properties, although indomethacin is known to be less effective at reducing pain in post-surgical inflammation such as that following arthroscopy or arthrotomy of the knee. ${ }^{20}$ Flurbiprofen and ketorolac have also shown, in several studies, an analgesic property at least similar to that of diclofenac. ${ }^{21,22}$ This property is, in part, mediated by the inhibition of prostaglandin synthesis. ${ }^{23}$

Experimental studies have demonstrated that diclofenac interferes with $\beta$-endorphins, causing a 4 -fold increase in their plasma levels in treated patients, thus suggesting that $\beta$-endorphins might contribute to the potent analgesic activity of diclofenac. ${ }^{24}$ In addition a potent analgesic effect demonstrated by NSAIDs with remarkably weak cyclooxygenase inhibition, such as that demonstrated by azapropazone, ${ }^{25}$ indicates that this effect could also be independent of the anti-inflammatory properties of NSAIDs. Chen et al. ${ }^{26}$ demonstrated that NSAIDs decrease sensory inflow from corneal polymodal nociceptor nerve fibres to the central nervous system when applied topically to the eye at doses and formulations used for therapeutic purposes. They hypothesised that this effect could be mediated by mechanisms other than cyclooxygenase inhibition, such as direct blockade of ionic channels in the nerve endings or other mechanisms interfering with the excitability of the polymodal nerve endings. Therefore, the analgesic characteristics of NSAIDs should be differentiated from their anti-inflammatory effect and from analgesia secondary to an anti-inflammatory response. Thus the assumption that all NSAIDs relieve pain only through an inhibition of prostaglandin synthesis is not completely satisfactory. ${ }^{27}$

The corneal hypoaesthetic effect shown by diclofenac could be due also to a mechanism of action different from that of cyclooxygenase inhibition, since indomethacin, flurbiprofen and ketorolac did not demonstrate such an effect.

In this study, commercially available eye drops instead of hospital-manufactured solutions were used. Although there were some differences in the vehicle present in the different solutions, it was decided to test the actual formulations that are prescribed to patients. On the other hand previous reports have shown a good corneal penetration and efficacy in the anterior chamber and in the corneal stroma of the NSAIDs used in the present study, ${ }^{28-30}$ and also an effect on the response of the corneal sensory nerve fibres to chemical irritation. ${ }^{26}$
As to the effect on corneal epithelium, previous studies have shown that the topical administration of diclofenac induced a toxic effect on the corneal epithelium with a high incidence of persistent epithelial defects in post-keratoplasty patients, ${ }^{31}$ while after photorefractive keratectomy delayed wound healing was demonstrated. ${ }^{32}$ These data are not in contrast with those of the present study, which showed a lack of epithelial toxicity consequent to the acute administration of diclofenac in normal subjects with a normal acute epithelium. It is noteworthy that even if diclofenac caused a reduction of corneal sensitivity this was not followed by epithelial damage, which was instead present in some patients following oxybuprocaine administration. This might be related to the greater imbalance of corneal sensitivity that followed administration of the topical anaesthetic.

As regards the duration of corneal hypoesthesia induced by diclofenac, previous reports showed various results using similar administration times. Szerenyi and associates $^{13}$ demonstrated in normal subjects a corneal hypoesthesia, following diclofenac administration, lasting only up to $40 \mathrm{~min}$ after application of the last drop; on the other hand Sun and Gimbel ${ }^{33}$ showed decreased corneal sensitivity with either diclofenac or ketorolac lasting at least $60 \mathrm{~min}$. An explanation of the reduced time of hypoesthesia in the report by Szerenyi et al. ${ }^{13}$ could be the higher number of measurements which were performed after every drug instillation; this could have determined either corneal irritation or a training effect, resulting in an increased patient awareness of the procedure.

There are some differences between the results of the present study and the results previously reported by other authors regarding the effect of ketorolac on corneal sensitivity. Sun and Gimbel $^{33}$ noticed a reduction in corneal sensitivity in a different experimental model: using a scheme of administration similar to that of our study, they simultaneously treated both eyes of each patient, one with ketorolac and the other with diclofenac. This could interfere, in some way, with the patients' responses to the test. Also Seitz and co-workers ${ }^{34}$ showed a decreased corneal sensitivity with both ketorolac and diclofenac instilled seven times at 5 min intervals; in this case the increased amount of drug instilled, with a probable cumulative effect, could be responsible for the reduced corneal sensitivity obtained with the ketorolac treatment.

In conclusion, the corneal hypoesthesia induced by diclofenac can be useful in reducing the pain and discomfort due to ocular inflammation and surgery. However, further studies are needed to determine the safety, efficacy and mechanisms of action of topical diclofenac. In fact, in chronic treatment, the effect of diclofenac on corneal nerves could be responsible either for an increased healing time of the corneal epithelium or for a neurotrophic epitheliopathy in those patients with conditions predisposing to epithelial damage, such as dry eye. 


\section{References}

1. Flach AJ. Cyclo-oxygenase inhibitors in ophthalmology. Surv Ophthalmol 1992;36:259-84.

2. Gwon A, Vaughan ER, Cheetham JK, De Gryse. Ocufen (Flurbiprofen) in the treatment of ocular pain after radial keratotomy. CLAO J 1994;20:131-8.

3. Arshinoff S, D'Addario D, Sadler C, Bilotta R, Johnson TM. Use of topical non-steroidal antiinflammatory drugs in excimer laser photorefractive keratectomy. J Cataract Refract Surg 1994;20 (Suppl):216-22.

4. Millodot M. The influence of age on the sensitivity of the cornea. Invest Ophthalmol Vis Sci 1977;16:240-2.

5. Riss B, Binder S, Riss P, Kemeter P. Corneal sensitivity during the menstrual cycle. Br J Ophthalmol 1982;66:123-6.

6. Kodama T, Hayasaka S, Setogawa T. Immunofluorescent staining and corneal sensitivity in patients suspected of having herpes simplex keratitis. Am J Ophthalmol 1992;113:187-9.

7. McNamara NA, Brand RJ, Polse KA, Bourne WM. Corneal function during normal and high serum glucose levels in dibetes. Invest Ophthalmol Vis Sci 1998;39:3-17.

8. Martin XY, Sapran AB. Corneal hypoesthesia. Surv Ophthalmol 1988;33:28-40.

9. Koenig SB, Berkowitz RA, Beuerman RW, McDonald MB. Corneal sensitivity after epikeratophakia. Ophthalmology 1983;90:1213-8.

10. Shivitz IA, Arrowsmith PN. Corneal sensitivity after radial keratotomy. Ophthalmology 1988;95:87-32.

11. Campos M, Hertzog L, Garbus JJ, McDonnell PJ. Corneal sensitivity after photorefractive keratectomy. Am J Ophthalmol 1992;114:51-4.

12. Loya N, Bassage S, Vyas S, del Cerro M, Park SB, Aquavella JV. Topical diclofenac following excimer laser: effect on corneal sensitivity and wound healing in rabbits. J Refract Corneal Surg 1994;10:423-7.

13. Szerenyi K, Sorken K, Garbus J, Lee M, McDonnell PJ. Decrease in normal human corneal sensitivity with topical diclofenac sodium. Am J Ophthalmol 1994;118:312-5.

14. Zaidman GW. Diclofenac and its effect on corneal sensation. Arch Ophthalmol 1995;113:262.

15. Aragona P, Fragalà I, Oteri FC, Battaglia F, Ferreri G. Effect of the topical administration of diclofenac sodium and indomethacin on corneal sensitivity in normal subjects. Vision Res 1995;35 (Suppl):S146.

16. Insel PA. Analgesic-antipyretics and antiinflammatory agents; drugs employed in the treatment of rheumatoid arthritis and gout. In: Goodman Gilman A, Rall TW, Nies AS, Taylor P, editors. Goodman and Gilman's The pharmacological basis of therapeutics, 8th ed. New York: Pergamon Press, 1990:638-81.

17. Buckley MM, Brogden RN. Ketorolac: a review of its pharmacodynamic and pharmacokinetic properties, and therapeutic potential. Drugs 1990;39:86-109.

18. Lemp MM. Report of the National Eye Institute/Industry workshop on clinical trials in dry eye. CLAO J 1995;21:221-32.

19. Cochet P, Bonnet R. L'esthesie cornéenne. Clin Ophthalmol 1960;4:3-27.
20. Laitinen J, Nuutinen L, Kiiskila EL, Freudental Y, Ranta P, et al. Comparison of intravenous diclofenac, indomethacin and oxycodone as post-operative analgesics in patients undergoing knee surgery. Eur J Anaesth 1992;9:29-34.

21. Bellamy N, Bensen WG, Ford PM, Huang SH, Lang JY. Double-blind randomized controlled trial of flurbiprofen-SR (ANSAID-SR) and diclofenac sodium-SR (Voltaren-SR) in the treatment of osteoarthritis. Clin Invest Med 1992;15:427-33.

22. Toscani F, Piva L, Corli O, Gallucci M, Speranza R, Tamburini M, De Conno F, Ventafridda V. Ketorolac versus diclofenac sodium in cancer pain. Arzneimittelforschung 1994;44:550-4.

23. Todd PA, Sorkin EM. Diclofenac sodium: a reappraisal of its pharmacodynamic and pharmacokinetic properties and therapeutic efficacy. Drugs 1988;35:244-85.

24. Martini A, Bondiolotti GP, Sarcerdote P, Pierro L, Picotto GB, et al. Diclofenac increases beta-endorphins plasma concentrations. J Int Med Res 1984;12:92-5.

25. Rainsford KD. The mode of action of azapropazone in relation to its therapeutic actions in rheumatic conditions and its major side-effects. In: Rainsford KD, editor. Azapropazone: 20 years of clinical use. Lancaster: Kluwer Academic, 1989:31-52.

26. Chen X, Gallar J, Belmonte C. Reduction by antiinflammatory drugs of the response of corneal sensory nerve fibres to chemical irritation. Invest Ophthalmol Vis Sci 197;38:1944-53.

27. McCormack K, Brune K. Dissociation between the antinociceptive and anti-inflammatory effects of the nonsteroidal anti-inflammatory drugs: a survey of their analgesics efficacy. Drugs 1991;41:533-47.

28. Ellis PP, Pfoff DS, Bloedow DC, Riegel M. Intraocular diclofenac and flurbiprofen concentrations in human aqueous humor following topical application. J Ocul Pharmacol 1994;10:677-82.

29. Frangouli A, Shah S, Chatterjee A, Morgan PB, Kinsey J. Efficacy of topical nonsteroidal drops as pain relief after excimer laser photorefractive keratectomy. J Refract Surg 1998;14(2 Suppl):S207-8.

30. Solomon KD, Turkalj JW, Whiteside SB, Stewart JA, Apple DJ. Topical $0.5 \%$ ketorolac vs $0.03 \%$ flurbiprofen for inhibition of miosis during cataract surgery. Arch Ophthalmol 1997;115:1119-22.

31. Shimazaki J, Saito H, Yang HY, Toda I, Fujishima H, Tsubota K. Persistent epithelial defects following penetrating keratoplasty: an adverse effect of diclofenac eyedrops. Cornea 1995;16:623-7.

32. Assouline M, Renard G, Arne JL, David T, Lasmolles C, Malecaze F, Pouliquen YJ. Prospective randomized trial of topical soluble $0.1 \%$ diclofenac versus placebo for the control of pain following excimer laser photorefractive keratectomy. Ophthalmic Surg Lasers 1998;29:365-74.

33. Sun R, Gimbel HV. Effects of topical ketorolac and diclofenac on normal corneal sensation. J Refract Surg 1997;13:158-61.

34. Seitz B, Sorken K, LaBree LD, Garbus JJ, McDonnell PJ. Corneal sensitivity and burning sensation. Arch Ophthalmol 1996;114:921-4. 